\title{
GENERIC DIFFERENCES AMONG NEW WORLD SPONGILLA-FLY LARVAE AND A DESCRIPTION OF \\ THE FEMALE OF CLIMACIA STRIATA (NEUROPTERA: SISYRIDAE)*
}

\author{
By Raymond J. Pupedis \\ Biological Sciences Group \\ University of Connecticut \\ Storrs, CT 06268
}

\section{INTRODUCTION}

While many entomologists are familiar, though probably uncomfortable, with the knowledge that the Neuroptera contains numerous dusty demons within its membership (Wheeler, 1930), few realize that this condition is balanced by the presence of aquatic angels. This rather delightful and appropriate appellation was bestowed on a member of the family Sisyridae by Brown (1950) in a popular account of his discovery of a sisyrid species in Lake Erie. Aside from the promise of possible redemption for some neuropterists, the spongilla-flies are an interesting study from any viewpoint.

If one excludes, as many do, the Megaloptera from the order Neuroptera, only the family Sisyridae can be said to possess truly aquatic larvae. Despite the reported association of the immature stages of the Osmylidae and Neurorthidae with wet environments, members of those families seem not to be exclusively aquatic; however, much more work remains to be done, especially on the neurorthids. The Polystoechotidae, too, were once considered to have an aquatic larval stage, but little evidence supports this view (Balduf, 1939).

Although the problem of evolutionary relationships among the neuropteran families has been studied many times, the phylogenetic position of the Sisyridae remains unclear (Tillyard, 1916; Withycombe, 1925; Adams, 1958; MacLeod, 1964; Shepard, 1967; and Gaumont, 1976). Until fairly recently, the family was thought to have evolved from an osmylid-like ancestor (Tillyard, 1916; Withycombe, 1925). This theory has been modified by a study of the new

*Manuscript received by the editor April 30, 1981. 
neuropteran family Neurorthidae. The neurorthids, originally considered (albeit doubtfully) by Parfin and Gurney (1956) to constitute a genus within the Sisyridae and later raised to the rank of subfamily by Nakahara (1958), were given family status by Zwick in 1967. Using a cladistic analysis comparing larval features, Zwick concluded that the Neurorthidae and Osmylidae were more closely related to each other than either was to the Sisyridae. Lack of strong synapomorphic larval or adult characters between Sisyridae and the neurorthid-osmylid clade prevents conjecture about possible relationships among the three families.

Sisyrids pass their entire larval life as parasites on freshwater sponges (Porifera: Spongillidae), feeding with mouthparts modified into long thin stylets. Just prior to pupation the larvae swim actively at night to the shore, where they emerge and seek cryptic sites in which to construct their cocoons. Following a brief prepupal stage of about 48 hours, the larva pupates; several days later the pupa chews a hole in the inner and outer layers of the cocoon and, after crawling out through the hole so that the thorax is free, it emerges as an adult, leaving the pupal skin protruding from the cocoon. Upon mating, the female oviposits several hundred eggs, usually singly, in the cracks, crevices, and pits of objects that overhang water. Each egg is covered by a flat protective layer of silk. Upon hatching, the larvae drop directly into the water and seek a sponge colony on which to complete the life cycle.

There are $\mathbf{4 5}$ described species of Sisyridae in four genera. Most species belong to the cosmopolitan Sisyra Burmeister (29 species) and the exclusively new world Climacia McLachlan (12 species). Despite their interesting sponge-associated life and their common occurrence, larvae of only eight species have been collected and studied. The larvae are not often found in entomological collections; when they are, they cannot be identified since diagnostic characters at the generic and species level are poorly known. This paper gives characters that can be used to identify to the generic level third instars of six new world temperate species and one neotropical species; a future paper will consider specific characters. Specimens examined: Sisyra vicaria Walker (Connecticut, $\mathrm{N}=30$ ), S. fuscata Fabricius (Alberta, $\mathrm{N}=8$ ), Climacia areolaris (Hagen) (Connecticut, $\mathrm{N}=27$ ), $C$. chapini Parfin and Gurney (New Mexico, $\mathrm{N}=5$ ), $C$. californica Chandler (California, $\mathrm{N}=3$ ), C. striata Parfin and Gurney (Panama, $\mathrm{N}=1$ ) and a Climacia species (Baja California, N 
=8). Distribution data on these specimens are found in Parfin and Gurney, 1956; Poirrier, 1969; Poirrier and Arceneaux, 1972; and Brown, 1974. Specimens were not available of the sole remaining new world sisyrid for which larvae have been collected, $S$. apicalis Banks. The specimen of $C$. striata is actually a prepupa, a stage which retains the larval features; it was found in a cocoon collected with others from which adults of $C$. striata were obtained. The larval specimens from Baja California were identified as Climacia from one deformed adult raised from a pupa found in the immediate vicinity of the larvae. Despite the adult's very close resemblance to C. californica, a species identification could not be made; the larvae are treated in this paper as belonging to an unknown species.

\section{LARVAL ChaRacteristics}

Two distinct features can be used to separate the third instars of Climacia species from those of Sisyra. On all sisyrid larvae, there is on both sides of the abdominal dorsal midline a small tergite, with two seta-bearing tubercles on the first abdominal segment and three on segments two through seven. The tergites on terminal segments eight and nine are modified and in a lateral position. The morphology of the tergites and tubercles on the first seven abdominal segments is essentially identical except for segment six. In Sisyra larvae the lateral-most tubercle is elongated to approximately twice the length of the others and its seta is thinner and longer than the other two (Fig. 1a). The middle tubercle on the tergite is clearly on the median side of the elongated tubercle, more so on $S$. vicaria than on $S$. fuscata. In Climacia larvae it is the median tubercle of the three that has become elongated, and no other tubercle is associated with it (Fig. 1b). As in Sisyra, the seta of the elongated tubercle is longer and thinner. The absolute length of this seta can be used to separate some species of Climacia (Poirrier and Arceneaux, 1972). Large, sharply pointed, blade-like cuticular projections ring the apex of the elongated tubercle of $C$. areolaris (Fig. 1c). In other Climacia species these projections are small or even microscopic (Fig. 1d). Both Sisyra species also possess these microscopic projections on the elongated tubercle.

The other distinguishing feature is located dorsally on the eighth abdominal segment. On abdominal segments one through seven, for all sisyrid species, a minute seta can be seen just medial to the 

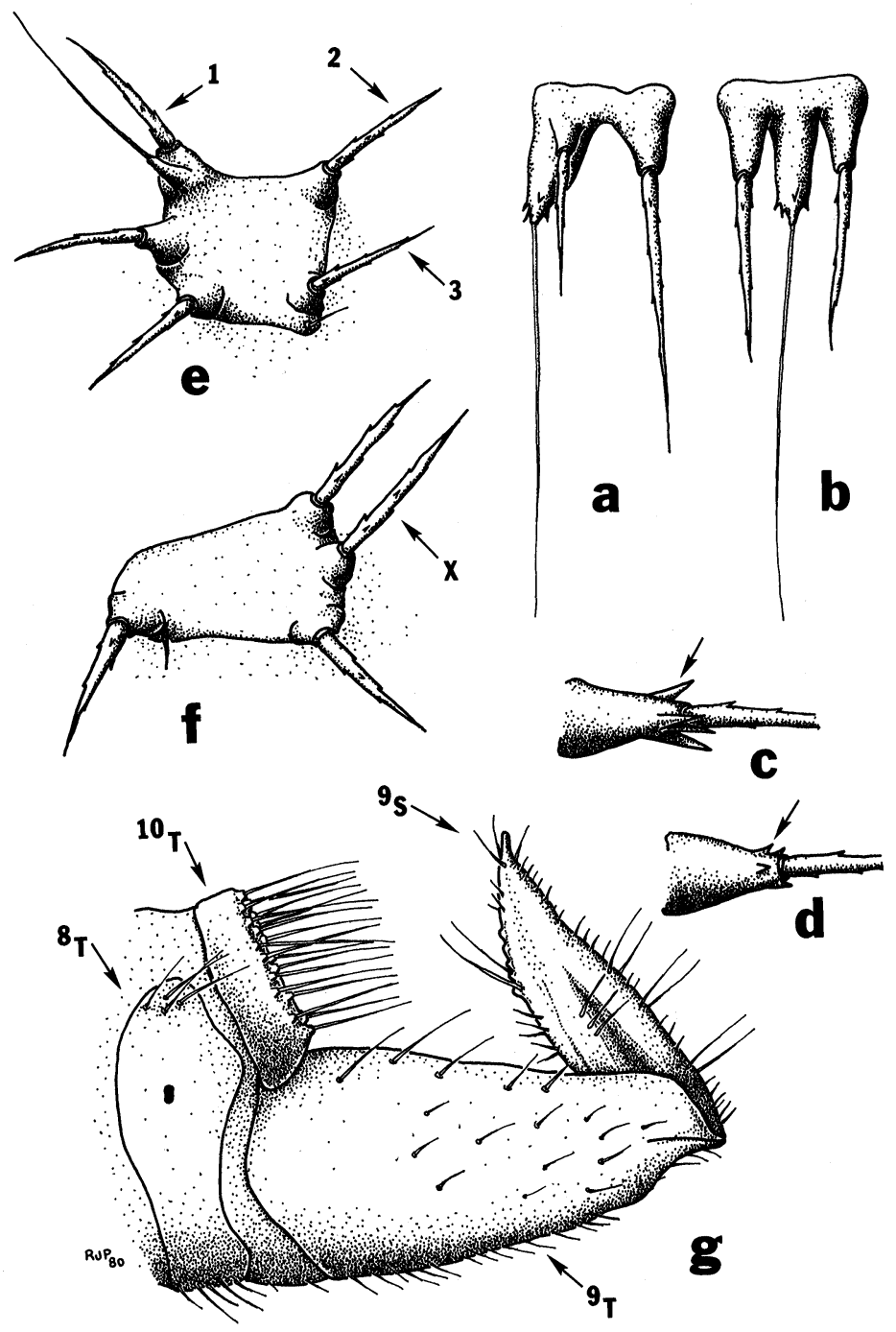

Figure 1. (see text for explanation of features). a, dorsal view of left sixth abdominal tergite of Sisyra species; b, same, Climacia species; c, tip of tubercle of Climacia areolaris; d, same, other Climacia and Sisyra species; e, dorsal view of left prothoracic tergite of Sisyra vicaria, typical of other sisyrid species; $f$, dorsal view of right mesothoracic or metathoracic tergite of $C$. californica and Baja Climacia species; g, Climacia striata, lateral view of female genitalia. 
tergites. The setae form two parallel rows, one on either side of the dorsal midline, that run the length of the abdomen. On the eighth segment of Sisyra larvae both setae remain small with no discernible bases. In the same location on Climacia species each seta is enlarged to form a large hair on a short distinct tubercle. Poirrier and Arceneaux (1972) noted this setal variation in southern specimens of $C$. areolaris, $C$. chapini, $S$. vicaria, and $S$. apicalis. Ventrally on the eighth abdominal segment is a similar pair of setae; on southern specimens of $S$. vicaria and $S$. apicalis the setae are sessile, but on $C$. areolaris and $C$. 'chapini they arise from tubercles (Poirrier and Arceneaux, 1972). This condition was not developed sufficiently to separate my northern specimens of $S$. vicaria from those of $C$. areolaris; both had bases. The above indicates geographic variability of this character, rossibly of a clinal nature.

A third, but more variable feature can be seen on the large pronotal tergites located to either side of the prothoracic midline. Each tergite has six prominent, setiferous tubercles (Fig. 1e). Generic identification can usually be made from the ratio A/B: the distance (A) between the anterior, horizontally paired tubercles (1 and 2) divided by the distance (B) between the longitudinally paired, medial tubercles ( 2 and 3$)$. Table 1 shows the ratio to be close to

TABle 1. Comparison of the ratio A/B obtained from the prothoracic tergites of seven sisyrid species (significance of differences between ratio values was analyzed using a modified T-test with alpha $=.05 ; \mathrm{N}$ is composed of measurements from the right and left sides of individual specimens).

\begin{tabular}{lcccl}
\hline SPECIES & $\mathrm{N}$ & $\mathrm{A} / \mathrm{B} \overline{\mathrm{X}}$ & $\mathrm{S}^{2}$ & RANGE \\
\hline Sisyra vicaria $^{1}$ & 46 & 1.3 & 0.0249 & $1.0-1.75$ \\
S. fuscata & 18 & 1.0 & 0.0082 & $0.85-1.14$ \\
Climacia areolaris $^{2}$ & 46 & 2.2 & 0.1487 & $1.45-3.0$ \\
Climacia species $_{\text {C. } \text { striata }}$ & 16 & 2.3 & 0.0473 & $2.0-2.75$ \\
C. californica & 2 & 2.3 & 0.0008 & $2.29-2.33$ \\
C. chapini & 4 & 2.0 & 0.0000 & 2.0 \\
& 9 & 2.0 & 0.0398 & $1.5-2.27$
\end{tabular}

1. Sisyra vicaria and $S$. fuscata differ significantly from all Climacia species and from each other.

2. Two significantly different groups of Climacia larvae are present with the members within the groups not significantly different from each other; $C$. areolaris, Climacia species, and C. striata versus $C$. californica and $C$. chapini. 
unity for Sisyra species and approximately two for Climacia. The distance between tubercles 2 and 3 is greatest for $S$. vicaria $(\overline{\mathrm{X}}=$ $0.245 \mathrm{~mm}, \mathrm{~N}=47$ ) but less for all the other sisyrid species (range of $\overline{\mathrm{X}}=0.065 \mathrm{~mm}$ to $0.165 \mathrm{~mm}$ ). Interestingly, $C$. striata from Panama is not significantly different $(\overline{\mathrm{X}}=0.065 \mathrm{~mm}, \mathrm{~N}=2$; t-test, alpha $=$ $.05)$ from any other sisyrid species except $S$. vicaria.

The pair of mesothoracic and metathoracic tergites on most Climacia and Sisyra have four setae each, one minute and sessile and three large and situated on tubercles. However, on $C$. californica and the Baja specimens of Climacia a fifth large seta and tubercle have been added to the lateral edge of each tergite (Fig. If, seta X). Absence of this feature from any of the other Climacia and Sisyra species suggests that the fifth seta represents a derived character state. However, until additional larval specimens of these and other sisyrid species are collected and studied, nothing more can be said about the phylogenetic value of the characters described above.

\section{CLIMACIA STRIATA}

In 1956 when Parfin and Gurney described C. striata from a single male specimen, the female was unknown. In 1978 five sisyrid cocoons were found on tree stumps protruding from the waters of Gatun Lake in Panama. One cocoon yielded a male striata, the other three produced striata females. The following is a description of the females and the cocoons.

Previous Records: Pinned male from La Chorrera, Panama, May 1916, collected by August Busck (Parfin and Gurney, 1956).

New Record: Panama: Canal Zone, Gatun Lake; 2 우 and their cocoons, from Gigante Bay on stump, 19 June 1978, collected by John Wenzel; 1 \&, 1 $\delta$ and their cocoons, from Juan Gallegos Bay on stump, 18 June 1978, collected by John Wenzel.

The male and two females have been deposited in the Museum of Comparative Zoology, Harvard University. One female and cocoon is retained in the author's collection.

DESCRIPTION OF FEMALE: Head with shiny, dark brown vertex, light yellowish-brown area extending from each eye anteriorly to antennae, another running transversely toward center of vertex along posterior margin of head; brown patch on frons, entirely covering clypeus, extending medially to center of face as 
narrow, light brown bar. Maxillary palpi yellow, terminal segment yellowish-brown. Basal antennal segment light yellow, dorsally brownish-yellow at distal margin; next six segments light yellowishbrown becoming darker brown dorsally; next eleven to thirteen segments dark brownish-black, changing abruptly after segments eighteen to twenty to a very pale yellow; latter pale yellow segments becoming brownish with approximately the distal 30 segments distinctly brown; fifty-seven segments in both the left and right antenna $(\mathrm{N}=1$ \% $)$. Legs generally pale yellowish-brown; mesothoracic and metathoracic coxae dark brown, prothoracic coxae pale yellow. Pronotum brown with darker mottling; mesonotum dark brown with large, light yellowish-brown patch in center with thin, dark, medial line posteriorly; metanotum dark brown with yellowish-brown medial patch; mesothoracic and metathoracic pleurites dark brown.

FOREWING: length $4.1 \mathrm{~mm}$, width $1.5 \mathrm{~mm}(\mathrm{~N}=3)$; wing venation and coloration identical to that of male, in both sexes $3 \mathrm{dr}$ runs from under pterostigma to $R_{S}$, not to $R_{2}+3$ as previously thought; $3 \mathrm{dr}$ distal to coalescence of $S_{C}$ and $R_{1}$.

HINDWING: length $3.6 \mathrm{~mm}$, width $1.5 \mathrm{~mm}(\mathrm{~N}=3)$; wing venation and coloration identical to that of male.

FEMALE GENITALIA: (Fig. 1g) eighth tergite broader dorsally, narrowing ventrally; ninth tergite with each lateroventral half large, elongate, anterior border convex and twice as wide as posterior border, dorsal margin sloping gently down and leveling off at posterior end, sharp ventrad slope just before articulation with ninth sternite, ventral margin sloping gently upward, slight concavity just before posterior apex, short horizontal ridge running anteriorly from posterior apex; ninth sternite not sharply bent at apex.

COCOON: The cocoons were spun on the ventral surfaces of dead leaves near the midrib. The morphology of the cocoon is almost identical to that of the larger cocoon of the nearctic species Climacia areolaris (Brown, 1952). The cocoon is composed of two separate parts (Fig. 2). The inner portion is an oblong hemispherical structure spun of fine grayish-white silk deposited randomly; it completely shields the insect from view. Mean width, length, and height are $1.7 \mathrm{~mm}, 2.9 \mathrm{~mm}$, and $1.1 \mathrm{~mm}$ respectively $(\mathrm{N}=5)$. Surrounding the inner cocoon and separate from it is an open- 


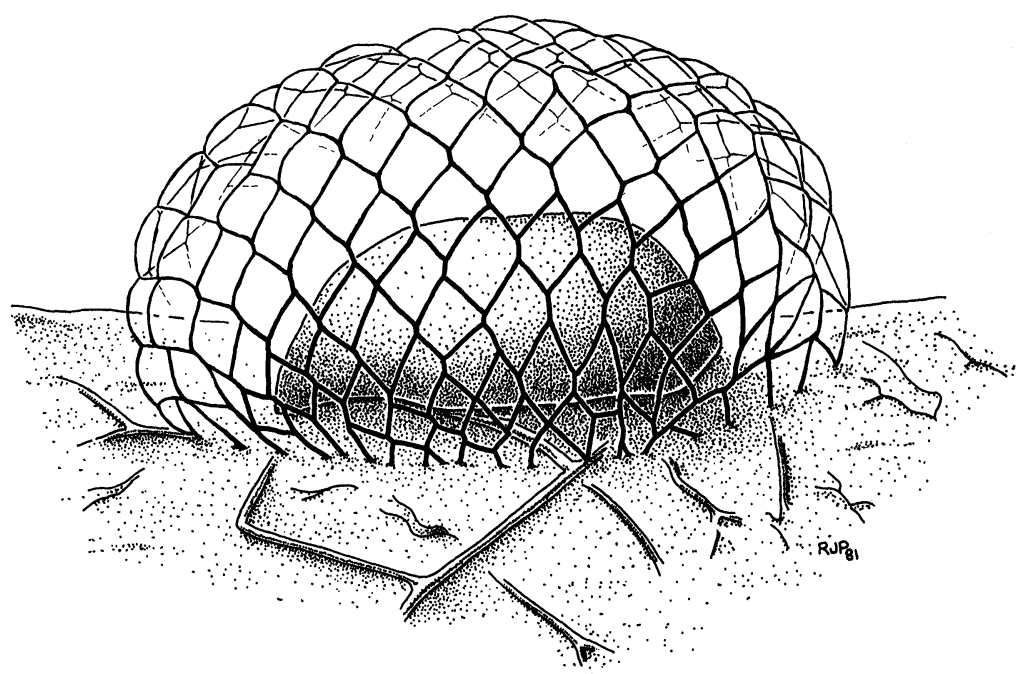

Figure 2. Lateral view of Climacia striata cocoon.

meshed hemispherical net. This outer mesh is formed by thick, individual strands of silk running in a sinusoid pattern from one side of the cocoon to the other. Each strand is connected to another at the "peak" of each "wave" and is reinforced by finer silk which gives the strands a frayed appearance. The mean width, length, and height of the outer mesh are $3.1 \mathrm{~mm}, 4.5 \mathrm{~mm}$, and $2.2 \mathrm{~mm}$ respectively $(\mathrm{N}=$ $5)$. From the upper portion of the inner cocoon there are strung horizontally from each side to the outer mesh three to four silk braces equidistant from each other. The overall appearance of this and all Climacia cocoons is one of a beautiful, lacy, silken halfbubble; when first seen hidden in a small dark niche and illuminated a brilliant white by the flashlight one immediately understands the fascination that sisyrids hold for entomologists.

\section{ACKNOWLEDGEMENTS}

I thank C. S. Henry and C. W. Schaefer of the University of Connecticut for constructive comments on this paper, and the following for kindly loaning larval and adult specimens: P. H. Arnaud (California Academy of Sciences), H. F. Clifford (University of Alberta), O. S. Flint, Jr. (National Museum of Natural 
History), R. E. Roughley (University of Alberta) and D. R. Shaw (Alberta). I would especially like to thank H. P. Brown (University of Oklahoma) for the larval specimens from Baja California and R. E. Silberglied (Harvard University) for the opportunity of examining the specimens of $C$. striata.

\section{ReFERENCES Cited}

Adams, P. A.

1958. Studies in the Neuroptera, with special reference to wing structure and evolution in the Osmyloidea. Unpublished Doctoral Dissertation, Harvard Univ., 105 pp., 79 figs.

BALDUF, W. V.

1939. The Bionomics of Entomophagous Insects. Pt. II. Chicago: John S. Swift Co., Inc., 384 pp.

Brown, H. P.

1950. Angels - or Just Parasites? Nature Mag. Feb: 74-75, 106.

1952. The life history of Climacia areolaris (Hagen), a neuropterous "parasite" of fresh-water sponges. Amer. Midl. Natur., 47: 130-160.

1974. Distribution Records of Spongilla Flies (Neuroptera: Sisyridae). Ent. News, 85(1): 31-33.

GAumonT, J.

1976. Jaws and digestive tube of Planipennia larvae. Ann. Sci. Nat. Zool. Biol. Anim., 18(2): 145-249.

MacLeod, E. G.

1964. A comparative morphological study of the head capsule and cervix of larval Neuroptera (Insecta). Unpublished Doctoral Dissertation, Harvard Univ., $528 \mathrm{pp}$.

NAKAHARA, W.

1958. The Neurorthinae, a New Subfamily of the Sisyridae (Neuroptera). Mushi, 32(2): 19-32.

Parfin, S. I. AND A. B. Gurney

1956. The spongilla-flies, with special reference to those of the western hemisphere (Sisyridae-Neuroptera). Proc. U. S. Nat. Mus., 105: 421529.

Poirrier, M. A.

1969. Some fresh-water sponge hosts of Louisiana and Texas Spongilla-flies, with new locality records. Amer. Midl. Natur., 81: 573-575.

Poirrier, M. A. ANd Y. M. Arceneaux

1972. Studies on Southern Sisyridae (Spongilla-flies) with a Key to the ThirdInstar Larvae and Additional Sponge-Host Records. Amer. Midl. Natur., 88: 455-458.

SHEPARD, F. D.

1967. The head capsule and cervix of adult Neuroptera (Insecta). A comparative study. Unpublished Doctoral Dissertation, Harvard Univ.

TILlYARD, R. J.

1916. Studies in Australian Neuroptera. No. IV. The families Ithonidae, 
Hemerobiidae, Sisyridae, Berothidae, and the new family Trichomatidae; with a discussion of their characters and relationships, and descriptions of new and little-known genera and species. Proc. Linn. Soc. New South Wales, 41(2): 269-332.

W HEELER, W. M.

1930. Demons of the Dust. New York: Norton \& Co.

WITHYCOMBE, C. L.

1925. Some aspects of the biology and morphology of the Neuroptera. With special reference to the immature stages and their possible phylogenetic significance. Trans. Entomol. Soc. London, 72(1924): 303-411.

ZwICK, P.

1967. Beschreibung der aquatischen larve von Neurorthus fallax (Rambur) und errichtung der neuen Planipennierfamilie Neurorthidae fam nov. Gewässer und Abwässer, Heft 44-45, S. 65/86, Bagel, Düsseldorf. 

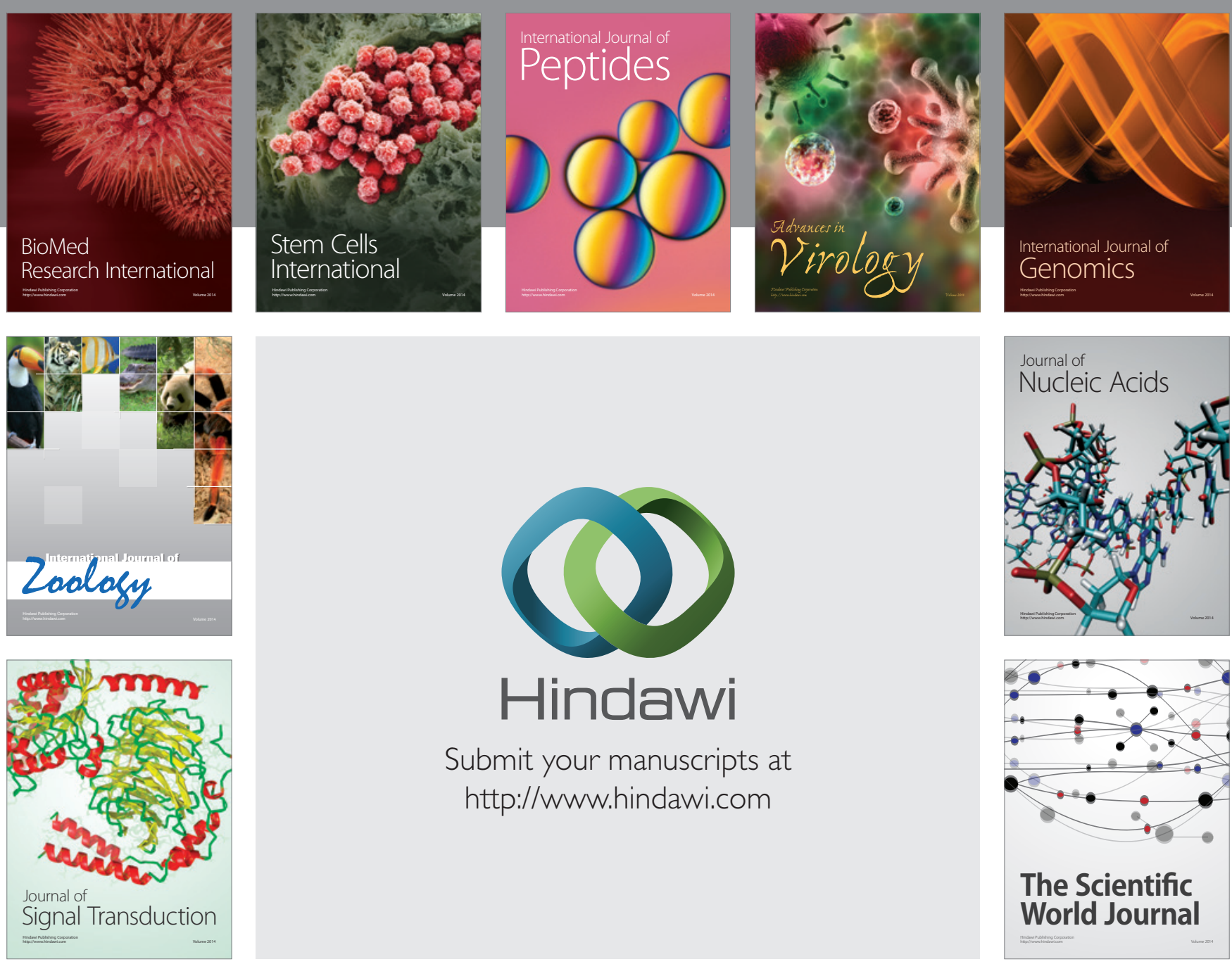

Submit your manuscripts at

http://www.hindawi.com
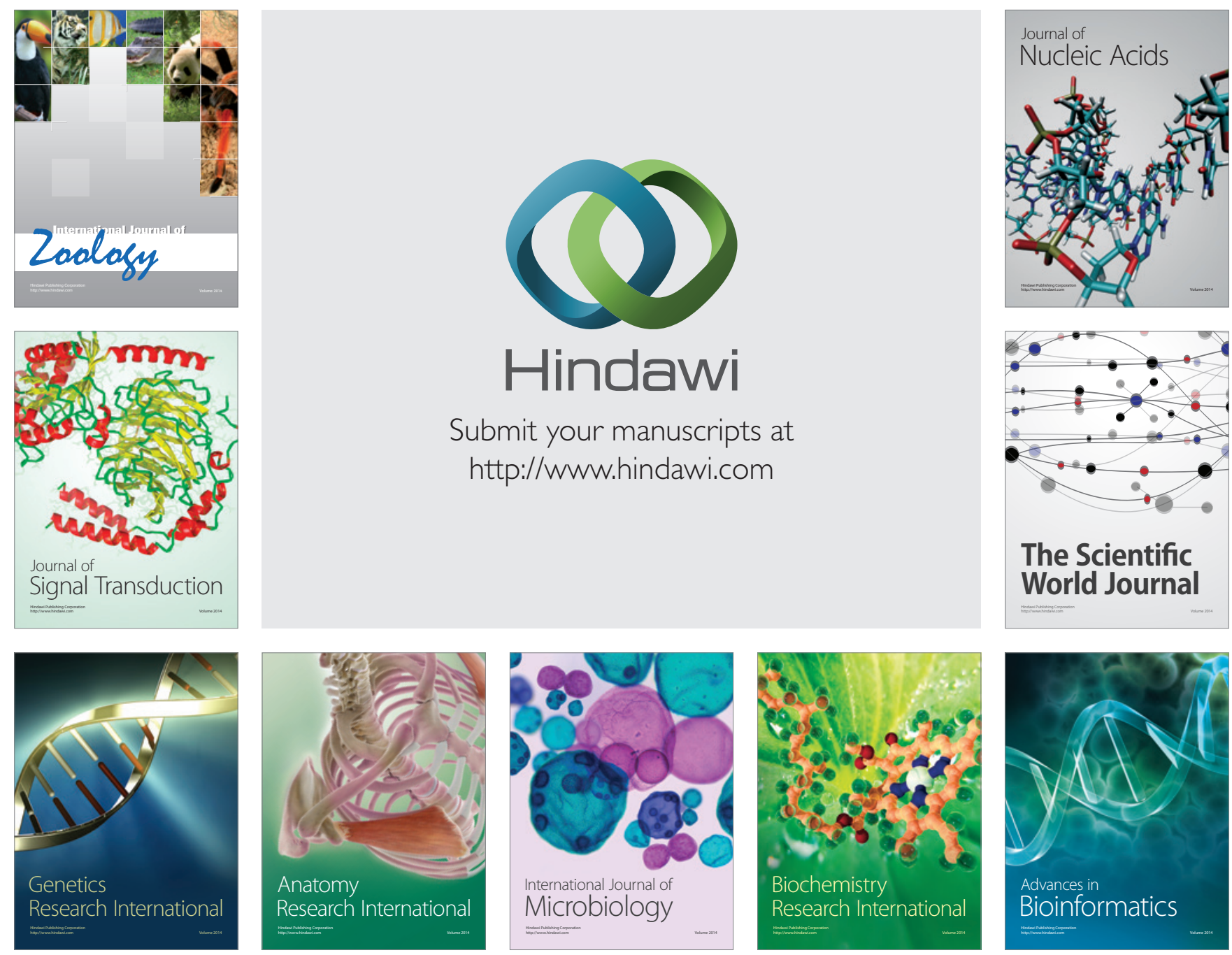

The Scientific World Journal
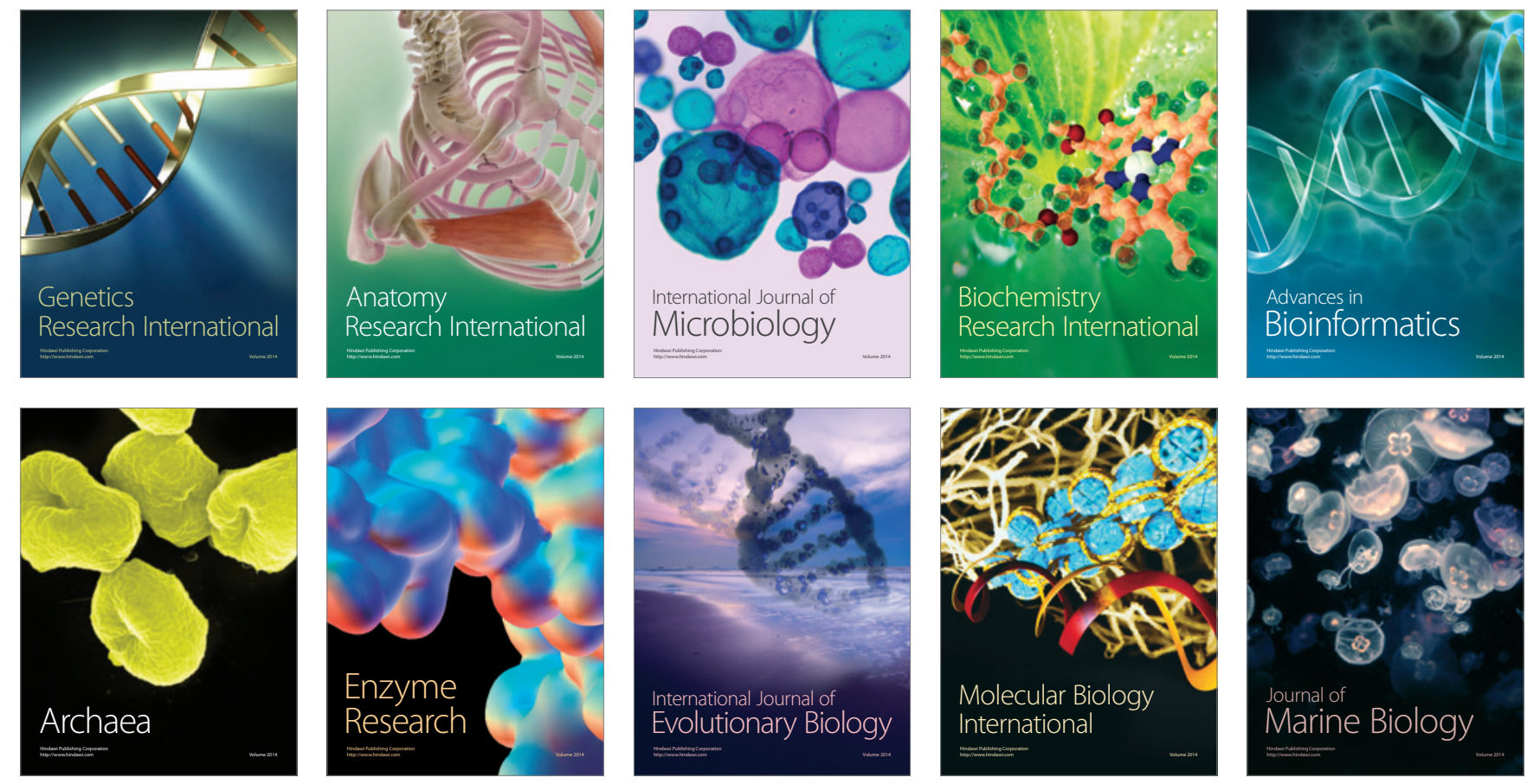